\title{
ADEUS PAPEL, MARCA-TEXTOS, TESOURA E COLA: INOVANDO O PROCESSO DE ANÁLISE DE CONTEÚDO POR MEIO DO ATLAS.TI
}

\author{
GOODBYE TO PAPER, HIGHLIGHTERS, SCISSORS AND GLUE: \\ INNOVATING THE CONTENT ANALYSIS PROCESS \\ THROUGH ATLAS.TI
}
Recebido em: 16/12/2014 Aprovado em: 27/02/2015 Avaliado pelo sistema double blind review Editora Científica: Manolita Correia Lima DOI: $10.13058 /$ raep.2015.v16n2.236

\section{SILVANA ANITA WALTER silvanaanita.walter@gmail.com UNIVERSIDADE ESTADUAL DO OESTE DO PARANÁ}

\author{
TATIANAMARCEDA BACH \\ PONTIFÍCIA UNIVERSIDADE CATÓLICA DO PARANÁ
}

\section{RESUMO}

O software Atlas.ti consiste em uma ferramenta para a análise de dados qualitativos que pode facilitar o gerenciamento e a interpretação desses dados. Entretanto, o emprego desse software tem sido bem menos frequente em estratégia, apesar da crescente utilização da análise de conteúdo nessa área. Este estudo objetivou apresentar, por meio de um exemplo, a aplicabilidade do software Atlas.ti na realização de análise de conteúdo temática na área de estratégia. O exemplo usado é o de uma pesquisa com dois escritórios de contabilidade de Curitiba, Paraná (PR), a cujos dirigentes se aplicou, como instrumento de coleta de dados, entrevista semiestruturada. Empregou-se, com o auxílio do software Atlas.ti 5.o, análise de conteúdo do tipo temática a qual deixou perceptível que os dois escritórios possuem uma trajetória similar; caracterizam-se como familiares; possuem ou possuíam centralização de poder; realizaram inovações; não possuem planos formalizados; e a maior parte de suas estratégias é emergente. O exemplo apresentado permitiu apresentar o processo de codificação, a criação de notas de pesquisa e de comentários, o estabelecimento de relações entre os elementos analisados e o agrupamento e gerenciamento de tais elementos. Espera-se que este estudo contribua para o estímulo da utilização do software Atlas.ti e auxilie na melhoria da consistência e do aperfeiçoamento das pesquisas qualitativas por meio da facilidade de verificação empírica.

Palavras-chave: Análise de conteúdo; Software Atlas.ti; Estratégia.

\section{ABSTRACT}

Atlas.ti software comprises a tool for the analysis of qualitative data that can facilitate its management and interpretation. However, the use of this software has been much less frequent in strategy, despite the increasing use of content analysis in this area.This study aimed to demonstrate, through an example, the applicability of Atlas.ti software in conducting thematic content analysis in the strategy area. The example used was a survey conducted on two accounting firms in Curitiba, Paraná (PR), and applied to the firm's directors, as a data collection instrument, through semi-structured interviews. With the help of Atlas.ti 5.0 software, thematic content analysis was undertaken and brought to light that the two offices have a similar trajectory; they are characterized as family members; they hold or held centralization of power; made innovations; do not have formalized plans; and, most of their strategies are emerging. The example used allowed for the demonstration of: the encoding process; the writing of research notes and comments; the establishment of relationships between the elements analyzed; and, the grouping and management of such elements. It is hoped that this study contributes to stimulating the use of Atlas.ti software and assists in improving the consistency and betterment of qualitative research through the ease of empirical verification.

Keywords: Content analysis; Atlas.ti software; Strategy. 


\section{INTRODUÇÃO}

O software Atlas.ti consiste em uma ferramenta para a análise de dados qualitativos podendo a sua utilização, segundo Cantero (2014), ser útil na formação em pesquisa qualitativa, visto que atribui maior visibilidade e transparência à análise de dados que, muitas vezes, representa a parte mais obscura do processo para os estudantes. Esse software teve sua primeira edição comercial em 1993 e, desde então, passou a ser empregado por diferentes áreas de conhecimento, como educação e administração, e em variados tipos de estudo, primeiramente pela grounded theory e, atualmente, por outras metodologias, como a análise de conteúdo.

Apesar da crescente utilização da análise de conteúdo em estudos de estratégia, o emprego de um software como o Atlas.ti é bem menos frequente nessa área. Pesquisadores mais ortodoxos, segundo Cantero (2014), relutam em utilizar softwares para auxiliar no processo interpretativo, pois o trabalho artesanal é a essência da análise qualitativa (CANTERO, 20I4). Por outro lado, Leite (2013) assevera que o Atlas.ti apresenta uma interface coerente com essa técnica de análise e pode auxiliar na organização e no tratamento de um número amplo de informações a ponto de as pesquisas não necessitarem ser tão restritivas na coleta de dados.

Dado o exposto, realizou-se o estudo ora apresentado com o objetivo de apresentar, por meio de um exemplo, a aplicabilidade do software Atlas.ti na realização de análise de conteúdo do tipo temática na área de estratégia. Espera-se contribuir com essa área de conhecimento, bem como para o aperfeiçoamento e desenvolvimento de pesquisas que empregam análise de conteúdo. Para tanto, apresenta-se a possibilidade de operacionalizar uma análise de conteúdo com o auxílio do Atlas.ti e como fazê-lo, bem como se discutem as vantagens e as limitações desse software.

Ressalta-se que se identificaram dois estudos que relacionam a análise de conteúdo e o Atlas.ti: o de Ferreira (20I2), que utiliza a análise de conteúdo com o auxílio do Atlas.ti para estudar a participação dos Setores de Educação e Saúde no Programa Saúde na Escola, e o de Leite (2013), que explora a possibilidade de utilização da análise de conteúdo com auxílio 
desse software para viabilização da Teoria Adaptativa por meio da concepção de um framework de empreendedorismo internacional. Apesar de esses estudos estabelecerem essa relação entre Atlas.ti e análise de conteúdo, não apresentam como esse software pode ser operacionalizado em uma pesquisa, pois apresentam outros objetivos.

O estudo que se realizou se encontra assim organizado neste artigo: na próxima seção, tem-se o exemplo de análise por meio do Atlas.ti, com destaque para o método de análise empregado, bem como a coleta e a análise dos dados; e, na terceira seção, encontram-se as considerações finais deste estudo nas quais se expõem as vantagens percebidas com a utilização do software enfocado. 


\section{ANÁLISE DE CONTÉUDO POR MEIO DO ATLAS.TI}

Nesta seção, apresenta-se um exemplo de análise de conteúdo realizada com o auxílio do software Atlas.ti 5.o. Ressalta-se que o exemplo apresentado consiste em uma pesquisa que teve por objetivo analisar o processo de desenvolvimento de estratégias e a atitude empreendedora dos dirigentes de dois escritórios de contabilidade de Curitiba, PR.

\section{MÉTODO DE ANÁLISE}

O Atlas.ti pode ser empregado em diferentes tipos de pesquisa, pois é flexível, podendo ser adaptado conforme os dados, objetivos e estratégia da pesquisa. Contudo, é mais bem aproveitado em pesquisas qualitativas e subjetivas que sejam, no mínimo, um pouco estruturadas. Isso porque, para a análise de cunho quantitativo e objetivista, existem outros softwares mais adequados disponíveis no mercado, como o Alcest ou N-Vivo, empregados para a verificação de frequência de palavras e geração de dados quantitativos. Por outro lado, em uma pesquisa de caráter subjetivo, não estruturada, muitas vezes não é empregada uma estratégia de análise sistemática, como a permitida pelo Atlas.ti. Dessa forma, objetivando a utilização de uma metodologia qualitativa e sistemática no exemplo apresentado, empregouse a análise de conteúdo.

De acordo com Bardin (2002), a análise de conteúdo consiste em técnicas de análise de mensagens por meio de procedimentos objetivos e sistemáticos, podendo ser qualitativos ou quantitativos, que admitam inferência a respeito do conteúdo da mensagem. No exemplo ora apresentado, empregou-se a análise de conteúdo qualitativa.

Ainda segundo Bardin (2002), existem diferentes unidades de registro que podem ser empregadas na análise de conteúdo, como a palavra, o tema, o objeto ou referente, o personagem e o documento. No presente exemplo, empregou-se o tema como unidade de registro, o qual consiste em uma unidade de significação de tamanho variado que é percebida naturalmente no texto analisado segundo critérios relativos à teoria que serve de guia à análise. Assim, a análise temática consiste em encontrar "núcleos de sentido" 
na comunicação e cuja presença é importante para a análise que está sendo realizada (BARDIN, 2002).

\section{COLETA DE DADOS}

No caso do exemplo apresentado, utilizaram-se, para a coleta de dados, entrevistas semiestruturadas com os proprietários dirigentes de dois escritórios de contabilidade de Curitiba, Paraná, e pesquisa documental, com consulta a manuais internos, a registros históricos e a matérias jornalísticas integrantes dos arquivos das empresas. Fizeram-se as opções mencionadas, pois o software Atlas.ti permite analisar e gerenciar diferentes tipos de documentos, como textos (respostas a questionários não estruturados, transcrição de entrevistas, relatórios de observação, documentos, cartas, texto jornalístico ou literário e outros), áudios (de entrevistas, de reuniões, de músicas e outros), imagens (fotos, desenhos, pinturas e outros) e vídeos (de pesquisas semiexperimentais, filmes, reportagens televisivas e outros).

No que se refere às entrevistas, elaborou-se, com base na base teórica adotada, um roteiro para analisar: a formação de estratégia e a atitude empreendedora, abrangendo clareza nos objetivos; os procedimentos precisos para alcançar os objetivos estratégicos e encontrar soluções para os problemas estratégicos; o ambiente empresarial; as limitações oriundas do ambiente; a elaboração de estratégias; existência de planos formais; o processo de escolha das estratégias; a existência de influência interna e/ ou externa nas escolhas estratégicas; a centralização ou descentralização das decisões; a postura em relação aos riscos; a inovação; e a necessidade de realização dos dirigentes. Anteriormente à realização das entrevistas, submeteu-se esse roteiro à avaliação de dois especialistas. Gravou-se cada entrevista e se fez a transcrição de forma integral para posterior análise em documentos de texto com o auxílio do software Atlas.ti.

\section{ANÁLISE DOS DADOS}

Conforme destacado, para o exemplo que se apresenta, optou-se pela análise temática de conteúdo por meio do software Atlas.ti 5.0 sobre o qual se discorre a seguir. 


\section{O software Atlas.ti}

O Atlas.ti consiste em um software de análise de dados qualitativos (ComputerAssisted Qualitative Data Analysis Software - CAQDAS). Seu protótipo inicial foi desenvolvido na Universidade Técnica de Berlin, Alemanha, como parte de um projeto multidisciplinar (1989-1992). A sigla "Atlas" significa, em alemão, Archivfuer Technik, Lebenswelt und Alltagssprache e pode ser traduzida como "arquivo para tecnologia, o mundo e a linguagem cotidiana". Já a sigla "ti" advém de text interpretation, ou seja, interpretação de texto (BANDEIRA-DE-MELLO, 2006).

O projeto original do Atlas.ti foi influenciado pela grounded theory, mas esse software pode ser empregado em diferentes estratégias de pesquisa (MUHR, 199I). De acordo com esse autor, o objetivo desse software não é automatizar o processo de análise, mas desenvolver uma ferramenta que apoie e facilite a interpretação humana.

Em 1993, Thomas Muhr lançou a primeira versão comercial de Atlas.ti, o que marcou o começo de sua empresa, a Scientific Software Development, atualmente, Atlas.ti GmbH. Nos anos seguintes, diversas versões do software foram lançadas, sendo que, no exemplo apresentado, empregou-se a versão 5.0.

O Atlas.ti apresenta quatro princípios norteadores da análise (BANDEIRADE-MELLO, 2006, p. 440):

- visualização: gerenciamento da complexidade do processo de análise, mantendo o contato do usuário com os dados;

- integração: a base de dados e todos os elementos construídos na análise são integrados em um único projeto, a unidade hermenêutica;

- casualidade (serendipity): promove a descoberta e os insights casualmente, isto é, sem a busca deliberada por aquilo que foi encontrado;

- exploração: a interação entre os diferentes elementos constitutivos do programa promove descoberta e insights.

O software Atlas.ti possui alguns elementos constitutivos estão apresentados no Quadro I. 
Quadro I Principais elementos constitutivos do Atlas.ti

\begin{tabular}{|c|c|}
\hline Elementos & Descrição \\
\hline $\begin{array}{l}\text { Unidade Hermenêutica } \\
\text { (Hermeneutic unit) }\end{array}$ & Reúne todos os dados e os demais elementos. \\
\hline $\begin{array}{l}\text { Documentos primários } \\
\text { (Primary documents) }\end{array}$ & $\begin{array}{l}\text { São os dados primários coletados. Em geral, são transcrições de } \\
\text { entrevistas e notas de campo, mas suportam figuras e áudio (a } \\
\text { versão atual também o faz em relação a imagens, áudio e vídeo). Os } \\
\text { documentos primários são denominados Px, sendo que x é o número } \\
\text { de ordem. }\end{array}$ \\
\hline $\begin{array}{l}\text { Citações } \\
\text { (Quotes/quotation) }\end{array}$ & $\begin{array}{l}\text { São segmentos de dados, como trechos relevantes das entrevistas } \\
\text { que indicam a ocorrência de código. A referência da citação é formada } \\
\text { pelo número do documento primário onde está localizada, seguido } \\
\text { do seu número de ordem dentro do documento. Também constam da } \\
\text { referência as linhas inicial e final, no caso de texto. }\end{array}$ \\
\hline Códigos (Codes) & $\begin{array}{l}\text { São os conceitos gerados pelas interpretações do pesquisador. } \\
\text { Podem estar associados a uma citação ou a outros códigos para } \\
\text { formar uma teoria ou ordenação conceitual. Sua referência é formada } \\
\text { por dois números: o primeiro refere-se ao número de citações ligadas } \\
\text { ao código; e o segundo, ao número de códigos associados. Os dois } \\
\text { números representam, respectivamente, seu grau de fundamentação } \\
\text { (groundedness) e de densidade teórica (density). }\end{array}$ \\
\hline $\begin{array}{l}\text { Notas de análise } \\
\text { (Memos) }\end{array}$ & $\begin{array}{l}\text { Descrevem o histórico da pesquisa. Registram as interpretações do } \\
\text { pesquisador, seus insights ao longo do processo de análise. }\end{array}$ \\
\hline $\begin{array}{l}\text { Esquemas gráficos } \\
\text { (Netview) }\end{array}$ & $\begin{array}{l}\text { Auxiliam a visualização do desenvolvimento da teoria e atenuam o } \\
\text { problema de gerenciamento da complexidade do processo de análise. } \\
\text { São representações gráficas das associações entre códigos. O tipo das } \\
\text { relações entre os códigos é representado por símbolos. }\end{array}$ \\
\hline $\begin{array}{l}\text { Comentários } \\
\text { (Comment) }\end{array}$ & $\begin{array}{l}\text { Podem estar presentes em todos os elementos constitutivos. Devem } \\
\text { ser utilizados pelos pesquisadores para registrar informações sobre } \\
\text { seus significados, bem como para registrar o histórico da importância } \\
\text { do elemento para a teoria em desenvolvimento. }\end{array}$ \\
\hline
\end{tabular}

Fonte: Adaptado pelos autores de Bandeira-de-Mello (2006).

Como destacado no Quadro I, todos os elementos de um projeto são compilados em uma Unidade Hermenêutica. Assim, caso o pesquisador esteja atuando em mais de um projeto/pesquisa, não há risco de misturar os materiais de cada projeto. Cada Unidade Hermenêutica pode agregar vários documentos primários, que são os materiais a serem analisados com o auxílio dos códigos atribuídos a citações, das notas de análise, dos esquemas gráficos e dos comentários.

Há poucos estudos sobre a aplicabilidade do Atlas.ti. Entre eles, destaca-se o de Bandeira-de-Mello e Cunha (2003) que explora o método de codificação 
da grounded theory por meio desse software. Com base nas três fases do processo de codificação na grounded theory (aberta, axial e seletiva), esses autores propõem um roteiro para operacionalizar o processo de codificação no Atlas.ti em quatro tarefas não lineares, pois permitem circularidade: codificar e rotular; desdobrar os dados (microanálise); descobrir e validar categorias e suas relações; integrar e refinar a teoria. A primeira tarefa é iniciada no documento primário que o pesquisador considera mais completo, de forma que, enquanto lê, identifica citações, objetivos e eventos importantes para serem codificados. O rótulo do código indica uma ideia ou conceito que possa ser utilizado em outros casos. Na segunda tarefa, o pesquisador registra interpretações, questionamentos e insights provisórios em notas de pesquisa. Após essa etapa, na terceira tarefa, identifica as categorias, as suas propriedades e as relações existentes entre elas. Essas categorias, propriedades e relações necessitam ser testadas nos dados empíricos e, portanto, validadas ou desprezadas. A última tarefa consiste em inferir, testar e validar a categoria central - com suas propriedades e dimensões - que integra todas as outras categorias em um esquema teórico principal.

Bandeira-de-Mello e Cunha (2003) observam que a utilização desse software pode reduzir a sobrecarga de tarefas mais operacionais, o que possibilita que o pesquisador se concentre mais nas descobertas e teorizações. Os autores também apontam, como outras possibilidades do Atlas.ti, a multiautoria e o processo de auditoria. O primeiro dá-se pela facilidade em compartilhar os projetos e pela probabilidade de utilização por diferentes usuários simultâneos; o segundo, por todo o processo de análise poder ser consultado por meio dos relatórios disponibilizados pelo software.

Cantero (20I4) igualmente aborda a possibilidade de utilização do Atlas. ti em estudos de grounded theory, com foco na área da educação, bem como indica algumas vantagens e desvantagens. Entre as vantagens, se encontram: a) incorporar dados sequencialmente sem a necessidade de realizar toda a coleta de dados para iniciar o tratamento desses dados; b) possibilitar a incorporação de diferentes tipos de dados, como textos, áudios, vídeos e imagens; c) por meio de recursos, como segmentação de citações, 
conceituação, registro de reflexões, categorização, estabelecimento de relações e construção de diagramas, facilitar a organização da análise para a apresentação das relações complexas, o que, por sua vez, facilita o desenvolvimento de modelos teóricos; d) agilizar a gestão, a pesquisa e a visualização de dados e códigos; e) possibilitar o tratamento de uma grande quantidade de informações, de forma que o pesquisador não necessite restringir a coleta de dados; f) permitir o trabalho simultâneo e virtual de diferentes pesquisadores, o que amplia a comunicação, a colaboração e a transparência no processo de análise (CANTERO, 20I4).

Quanto às desvantagens da utilização do Atlas.ti, Cantero (20I4) afirma que podem ser expressas como tendência a: a) acreditar que esse software realizará o trabalho interpretativo, o que se constitui em um exercício intelectual do pesquisador; b) exigir que seja utilizado esse software em específico por já conhecê-lo ou por acreditar que agilizará o processo, mesmo que não se alinhe ao objetivo e ao método da pesquisa; e c) perder a visão holística do fenômeno em estudo em virtude do trabalho de fragmentação. Não obstante apresente vantagens e desvantagens, o Atlas. ti, conforme Cantero (20I4), pode contemplar, na área de educação, a diversidade das pesquisas qualitativas, visto que aceita diferentes tipos de dados. Sendo assim, é possível ultrapassar o nível descritivo para alcançar o nível conceitual que contribui para a teorização da pesquisa em educação.

Ainda no que tange ao Atlas.ti, Dolan e Ayland (200I) realizaram um estudo comparativo entre três opções de análise de entrevistas semiestruturadas com e sem a utilização desse software: holística e interpretativa (leitura das transcrições e anotação de pensamentos interpretativos), corte de segmentos das entrevistas e sua alocação em códigos sem a utilização de software, e o uso do Atlas.ti As três formas de análise apresentaram resultados semelhantes, exceto pelo fato de a análise holística e interpretativa ter possibilitado a identificação do "tipo" de respondentes, o que não ocorreu nas outras análises. Esses autores elucidam que isso pode ter ocorrido porque, nos outros dois tipos de análise, os pesquisadores se concentraram em segmentos das entrevistas em relação ao todo, e não em cada entrevistado individualmente. Com base nisso, Dolan e Ayland (200I) asseveram que 
há métodos de análise, como grounded theory e similares, que podem obter mais vantagens com o uso de softwares do que outros mais dependentes do contexto, como etnometodologia e interacionismo simbólico.

Já Ferreira et al. (2012) utilizaram o Atlas.ti em uma pesquisa sobre a participação dos Setores de Educação e Saúde no Programa Saúde na Escola. Tiveram como ponto de partida os diplomas normativos emitidos para esse Programa e realizaram análise de conteúdo dos dados nas três etapas propostas por Bardin (2002): pré-análise; exploração do material; realização de inferências e interpretações. A pré-análise consiste na leitura flutuante dos materiais coletados para definir quais serão analisados; na elaboração das primeiras hipóteses; na definição dos índices e indicadores; e na preparação dos materiais. Ferreira et al. (2012) destacam que, no Atlas. ti, os materiais selecionados para análise correspondem aos documentos primários, e os indicadores, aos códigos da Unidade Hermenêutica. No que concerne à exploração do material, segunda etapa, foi realizada a codificação dos documentos primários, ou seja, a identificação de unidades de sentido (citações no Atlas.ti) relevantes para a pesquisa e atribuição de um nome ou conceito (código no Atlas.ti) a essa unidade. Alguns códigos, segundo Ferreira et al. (2012), foram obtidos no referencial teórico; outros, no objeto e na hipótese; e outros, ainda, emergiram durante as análises. Nessa etapa, também pode ser realizada a categorização (criação de famílias no Atlas. ti), que consiste na classificação, na diferenciação e no reagrupamento dos elementos de acordo com critérios de análise, bem como a análise dos fragmentos e de seus significados, estabelecendo-se ligações (associações) entre elementos. Quanto à realização de inferências e interpretações dos dados tratados, última etapa, o Atlas.ti a facilita por meio das associações criadas durante a etapa anterior e do uso de representações gráficas dessas relações na forma de redes (FERREIRA et al., 20I2).

Outro estudo realizado com o auxílio do Atlas.ti foi o de Leite (20I3) que explorou, por meio da utilização de análise de conteúdo, como a Teoria Adaptativa pode ser viabilizada na concepção de um framework de empreendedorismo internacional. Tal autor identificou que o software auxiliou na manipulação do amplo número de informações coletadas e que 
apresenta uma interface que favorece a utilização da análise de conteúdo, além de que a análise de conteúdo com auxílio do Atlas.ti se mostrou coerente com o corte longitudinal dos dados. Leite (2013) apresenta, porém, a ressalva de que alguns protocolos de pesquisa são fundamentais nesse tipo de estudo, como domínio teórico; criação de um arcabouço teórico inicial a ser comparado com os dados empíricos; clareza dos construtos a serem examinados; e busca por confiabilidade e validade para os resultados.

Conforme exposto, o estudo de Ferreira et al. (2012) e o de Leite (20I3) utilizaram a análise de conteúdo por meio do Atlas.ti, mas com um diferencial. Enquanto o primeiro realizou uma pesquisa utilizando análise de conteúdo com o auxílio desse software, Leite (2013) explorou a possibilidade de utilizá-lo nesse tipo de análise para viabilização da Teoria Adaptativa.

O que se expôs nessa subseção, com base nos autores Cantero (20I4), Bandeira-de-Melo e Cunha (2003), Ferreira et al. (2012) e Leite (2013), possibilita inferir que o software Atlas.ti apresenta vantagens e desvantagens a serem analisadas antes de sua utilização na pesquisa. Como vantagens, destaca-se que: esse software é flexível e que seu uso pode ser adaptado para diferentes pesquisas; torna possível, conforme já mencionado, o gerenciamento e a análise de diversos e diferentes tipos de documentos (texto, áudio, imagens e vídeos) (LEITE, 20I3; CANTERO, 20I4); e pode agilizar e facilitar o processo de análise, visto que o tempo de tratamento de um grande banco de dados, como no caso de diversas entrevistas, pode ser reduzido substancialmente (BANDEIRA-DE-MELO; CUNHA, 2003; CANTERO, 20I4). Além disso, o Atlas.ti possui ferramentas para o registro de todas as etapas da análise, o que facilita a comprovação empírica das interpretações e das alterações no decorrer do processo (BANDEIRADE-MELO; CUNHA, 2003) e permite a visualização gráfica das relações semânticas e a construção de gráficos semânticos (BANDEIRA-DE-MELO; CUNHA, 2003; FERREIRA et al., 20I2; CANTERO, 20I4). Outra vantagem é que, no caso de haver mais de um pesquisador trabalhando em um único projeto, como em grupos de pesquisa, o software permite a padronização dos códigos, facilitando a análise em grupo, bem como possibilita a atuação 
de diferentes pesquisadores em um único projeto de pesquisa (BANDEIRADE-MELO; CUNHA, 2003; CANTERO, 20I4).

Como desvantagens do uso do Atlas.ti, ressalta-se a necessidade de o pesquisador considerar os custos para aquisição desse software e o tempo de aprendizado para sua operacionalização e adaptação à pesquisa. A utilização do Atlas.ti e de outros softwares de análise de dados qualitativos igualmente apresentam, se mal empregados, alguns riscos, como o distanciamento da realidade dos sujeitos da pesquisa (RICHARDS; RICHARDS, I99I); o excesso de códigos advindos da facilidade de codificação, que pode dificultar as análises (GILBERT, 2002); a perda da visão holística dos dados (DOLAN; AYLAND, 200I; CANTERO, 20I4); o foco nos procedimentos e possibilidades do software, que pode inibir a descoberta de novos insights (GILBERT, 2002); e a automatização da interpretação, que pode obstar a reflexão.

Em síntese, destacou-se, nesta subseção, algumas informações sobre o Atlas.ti e a sua utilização, o que trouxe subsídios para ressaltar que esse software pode ser um aliado de pesquisadores que tenham interesse em utilizá-lo e disponibilidade em arcar com os custos de aquisição e aprendizagem para empregá-lo da maneira apropriada. Ademais, para um bom aproveitamento do Atlas.ti, considera-se importante que os pesquisadores conheçam seus recursos e limitações, bem como a adequação a cada nova pesquisa e a contribuição que ele pode ou não proporcionar.

\section{Procedimento de análise}

Realizou-se a análise de conteúdo do tipo temática com o auxílio do software Atlas.ti versão 5.0 por meio da identificação das unidades de significação (citação ou quote/quotation) e atribuição de um rótulo (código ou code) inspirado na teoria de base para representar a ideia presente. De acordo com Bardin (2002), a codificação consiste na transformação dos dados brutos, o que, por meio de um recorte, permite atingir uma representação do conteúdo capaz de evidenciar para o pesquisador características presentes no material analisado. Dessa forma, codificaram-se todas as citações pertinentes ao objetivo da pesquisa. A codificação de dados, segundo Cantero (20I4), é uma das possibilidades oferecidas pelo Atlas.ti que envolve 
a marcação de fragmentos para, então, codificar e obter uma lista de códigos descritivos.

Posteriormente, objetivando a comparação entre os dois escritórios em análise, optou-se pela construção de duas famílias (families): uma para cada escritório. Visualizaram-se essas famílias por meio de um esquema gráfico de relações semânticas (networds). Também se construiu uma superfamília (super family) para análise das semelhanças entre os dois escritórios.

No decorrer do processo, sempre que pertinente, criaram-se os comentários para os documentos, as citações, os códigos, asfamílias, as superfamíliase as notas de análise. Procedeu-se dessa forma com o objetivo de registrar informações importantes para consulta futura, como comentários complementares, significados e síntese de resultados. Como destaca Cantero (2014), fragmentos de codificação podem ser complementados com notas, permitindo a incorporação de ideias ou reflexões teóricas do pesquisador. Além disso, estabeleceram-se relações entre citações (anchors ou âncoras) e entre códigos (links ou vínculos) que também puderam ser visualizadas no esquema gráfico.

\section{Exemplo de análise}

Em todo projeto de pesquisa, é importante que o pesquisador esteja previamente embasado em uma teoria para realizar a análise e proceder à codificação, exceto se estiver empregando grounded theory. Normalmente, quanto mais o pesquisador conhecer a teoria de base, mais conseguirá explorá-la nas análises. Para apresentação desse exemplo, empregaram-se, como teorias de base e modelo de análise, as influências ocorridas durante o processo de desenvolvimento de estratégias, destacadas por Bailey e Avery (1998); e os elementos associados à atitude empreendedora, indicados por Carland, Carland e Hoy (1992).

O processo de desenvolvimento de estratégias é abordado por Bailey e Avery (1998) por meio de seis dimensões que procuram abranger diferentes influências ocorridas durante esse processo: planejamento, incremental, cultural, política, comando e escolha imposta. Além disso, Bailey e Avery (1998) destacam, em relação a cada uma delas, como ocorre o desenvolvimento da estratégia e outras características pertinentes. 
Na dimensão planejamento, de acordo com Bailey e Avery (1998), a estratégia é desenvolvida por meio de um processo de planejamento analítico, intencional e sequencial. Além disso, tem-se, nessa dimensão, que: (a) as estratégias da organização são o resultado de procedimentos metódicos, planejados, sequenciais e racionais; (b) os objetivos estratégicos são estabelecidos pelos executivos seniores; (c) a organização e o ambiente são analisados; (d) são estabelecidos objetivos definidos e precisos; (e) são desenvolvidos planos precisos para implantação; e (f) a estratégia é explicitada na forma de planos detalhados (BAILEY; AVERY, 1998).

A segunda dimensão - a incremental -, refere-se, segundo Bailey e Avery (1998), à estratégia desenvolvida de maneira evolutiva e proposital por um processo de interação e adaptação de tentativa e erro. Essa dimensão também apresenta outras características, a saber: (a) a estratégia é ajustada continuamente para se adequar às mudanças no ambiente operacional; (b) $\mathrm{o}$ ajuste das opções estratégicas é avaliado continuamente; (c) o compromisso inicial com uma estratégia é incerto e sujeito à revisão; (d) a estratégia é desenvolvida por experimentação e implantação gradual; (e) as opções prósperas ganham recursos adicionais; e (f) a estratégia é desenvolvida por meio de mudanças em pequena escala (BAILEY; AVERY, 1998).

Na dimensão cultural, terceira apontada por Bailey e Avery (1998), a estratégia é dirigida e guiada por aspectos culturais e pela cultura das organizações, bem como pelas suposições e conviç̧ões partilhadas por seus membros. Tais autores também assinalam que, nessa dimensão: (a) o "modo de fazer as coisas" da organização impacta na direção estratégica; (b) estratégias evoluem conforme um conjunto de suposições compartilhadas que existem na organização; (c) um conjunto central de suposições compartilhadas baseado na experiência e na história da organização guia ações estratégicas; (c) a história organizacional dirige a procura pela seleção de opções estratégicas; e (d) a estratégia não ajustada à cultura da organização encontra resistência.

Para Bailey e Avery (1998), a quarta dimensão - a política -, ressalta que a estratégia é desenvolvida por um processo de barganha, negociação e influência entre os grupos de interesses internos às organizações. 
Igualmente são características dessa dimensão: (a) as estratégias são desenvolvidas por meio de negociação e barganha entre grupos; (b) os grupos de interesses buscam atingir seus próprios objetivos; (c) a influência em formulação de estratégia aumenta com o poder; (d) o poder vem da habilidade de criar ou de controlar o fluxo de recursos escassos; (e) grupos de interesses formam alianças para promover a estratégia desejada por eles; (f) o controle e a provisão de informação também são uma fonte de poder; e (g) uma estratégia aceitável pelos grupos de interesses mais poderosos é desenvolvida (BAILEY; AVERY, 1998).

Na dimensão de comando, a quinta, a estratégia é definida e determinada por um indivíduo poderoso da organização (BAILEY; AVERY, 1998). Além disso, esses autores ressaltam que: (a) um indivíduo é a força motriz da estratégia da organização; (b) a estratégia é principalmente associada ao poder institucional de um grupo individual ou pequeno; (c) a estratégia representa as aspirações desse indivíduo para o futuro da organização; (d) o indivíduo se torna a representação da estratégia para a organização; e (e) um indivíduo tem um alto grau de controle sobre a estratégia.

A sexta e última dimensão, escolha imposta, aponta, sob a ótica de Bailey e Avery (1998), que a estratégia é resultado de pressões externas às organizações que restringem a habilidade dessas organizações para determinar sua própria direção estratégica. Como características dessa dimensão, tem-se, também, que: (a) as estratégias são prescritas pelo ambiente operacional; (b) a escolha estratégica é restringida por forças externas que a organização é incapaz de controlar; (c) a mudança estratégica é instigada de fora da organização; (d) as organizações não podem influenciar seus ambientes operacionais; e (e) barreiras no ambiente restringem amplamente a mobilidade estratégica (BAILEY; AVERY, 1998).

A breve exposição das seis dimensões de Bailey e Avery (1998), por meio das quais se desenvolvem estratégias, permite perceber uma diversidade de concepções a respeito do desenvolvimento dessas estratégias, fornecendo, assim, uma base abrangente para analisar como ocorre nas organizações.

A segunda teoria de base utilizada no exemplo de análise refere-se à atitude empreendedora. Ressalta-se que, nos estudos sobre empreendedorismo, 
há um debate a respeito da definição de empreendedor. Para muitos pesquisadores, o indivíduo é ou não é empreendedor. Carland, Carland e Hoy (1992), ao contrário, sugerem que o empreendedorismo poderia ser, na realidade, um continuum, ou seja, existem diferentes níveis de empreendedorismo, com possibilidade de evolução durante a trajetória. Adotando essa perspectiva, Carland, Carland e Hoy (1992) propuseram um modelo conceitual que busca entender as diferentes categorias de empreendedores, de acordo com a força empreendedora de cada indivíduo. Para Gimenez (2008), no modelo proposto por Carland, Carland e Hoy (1992), a categorização dos indivíduos baseia-se nos objetivos esperados para o futuro empreendimento.

Carland, Carland e Hoy (1992) realizaram uma ampla revisão de literatura que possibilitou a eles a percepção de que o comportamento empreendedor está associado, principalmente, a quatro elementos - personalidade, propensão para a inovação, propensão ao risco e postura estratégica - os quais foram empregados para elaboração de seu modelo conceitual.

Gimenez (2008) procurou descrever e detalhar os quatro elementos apontados por Carland, Carland e Hoy (1992). O elemento personalidade relaciona-se à necessidade de realização e à criatividade. Indivíduos com maior necessidade de realização possuem maior propensão a assumir tarefas difíceis e metas de longo prazo, além de costumeiramente possuírem maior preocupação em atingir a excelência em suas atividades (GIMENEZ, 2008). Já a criatividade, segundo essa autora, pode ser percebida, principalmente, na resolução de problemas, por meio da forma como o empreendedor aplica seu conhecimento e suas habilidades, bem como por sua motivação para a ação.

O segundo elemento, propensão para a inovação, está intimamente relacionado ao empreendedorismo e pode ser percebido na capacidade de identificar e aproveitar as oportunidades, além de que pessoas mais empreendedoras provavelmente buscarão produtos e processos distintos dos produzidos e empregados anteriormente (GIMENEZ, 2008).

A propensão ao risco, terceiro elemento da base conceitual de Carland, Carland e Hoy (1992), é definida por Gimenez (2008) como uma tendência 
para evitar ou aceitar situações de incerteza em relação aos resultados. Nessas situações, os indivíduos mais empreendedores possivelmente terão maior probabilidade de aceitar os riscos e sentirão menos desconforto com a existência deles (GIMENEZ, 2008).

Por fim, a postura estratégica relaciona-se à existência ou não de pensamento em longo prazo, de monitoramento do contexto, principalmente quanto às condições sociais e econômicas e de envolvimento em atividades de planejamento formal (GIMENEZ, 2008). Para a autora, é possível perceber a postura empreendedora da pessoa por meio da forma como identifica uma oportunidade, organiza e aplica os recursos para transformá-la em produtos ou serviços.

Com base no exposto, afirma-se que o modelo de Carland, Carland e Hoy (1992) pode ser útil para analisar a gestão estratégica de organizações, principalmente por meio da mensuração do elemento de postura estratégica. O instrumento desenvolvido por esses autores tem sido utilizado e foi validado por pesquisas anteriores realizadas no Brasil, tais como as de Inácio Júnior (2002) que abordou o empreendedorismo em empresas incubadas.

\section{Análise dos dados}

Para análise, após criar um projeto (Unidade Hermenêutica) inserindo todos os arquivos que o pesquisador deseja utilizar, é importante realizar uma leitura de todo o material coletado. Essa leitura tem o objetivo de ajudar o pesquisador a não perder a visão holística da pesquisa (DOLAN; AYLAND, 20or; CANTERO, 20I4), o que se torna mais difícil depois de iniciado o processo de codificação. Bardin (2002) denomina essa etapa, na análise de conteúdo, de pré-análise, conforme já mencionado. Ao longo dessa leitura, o pesquisador pode utilizar a ferramenta comentários (memos) para registrar suas primeiras impressões, hipóteses e comentários sobre o material, como exemplificado na Figura I. 
Figura I Exemplo de criação de comentário com base na leitura prévia do material

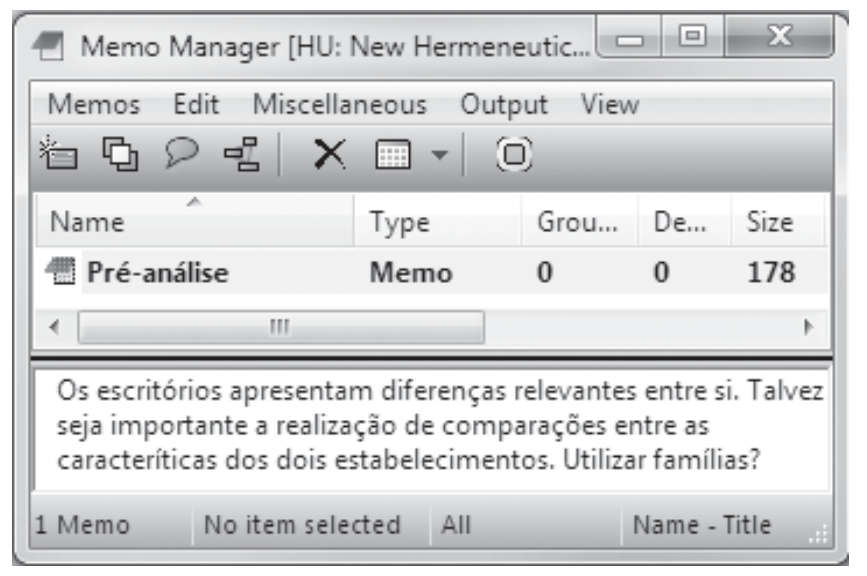

A Figura I exemplifica um comentário do tipo livre (não vinculado a um elemento do projeto) visualizado por meio do Administrador de Comentários. Ressalta-se que esses comentários podem ser facilmente editados, de forma que o pesquisador não precisa se inibir em registrar suas primeiras impressões, pois podem ser revisadas e alteradas em qualquer momento.

Realizada a leitura, o pesquisador pode iniciar o processo de codificação, conforme exemplo apresentado na Figura 2. 
Figura 2 Exemplo de atribuição de código a uma citação

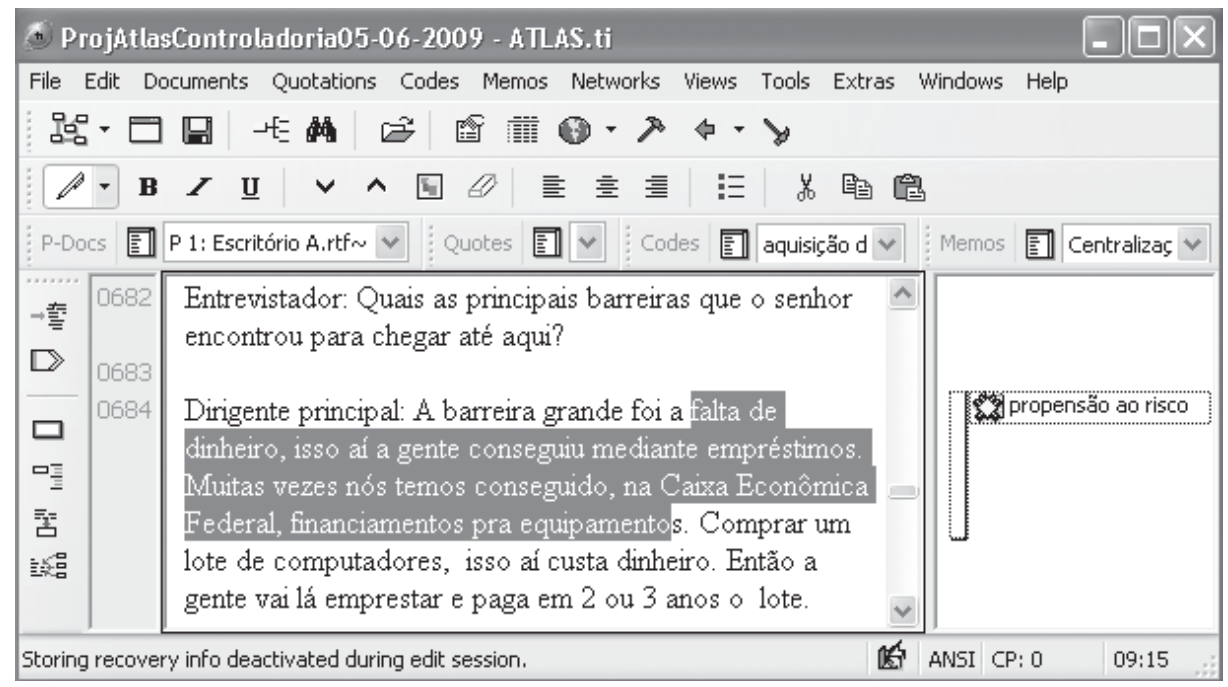

Na Figura 2 nota-se que o Escritório A apresenta propensão ao risco no tocante à realização de empréstimos. A escolha desse código está embasada na teoria (uma das categorias de análise a respeito da atitude empreendedora) e, como recomenda Bandeira-de-Mello e Cunha (2003), pode ser útil para outras citações. A propensão ao risco, segundo Gimenez (2008), é uma tendência em aceitar ou evitar situações de incerteza sobre os resultados. Ressalta-se que, nesse momento de seu desenvolvimento, o dirigente do Escritório A não possuía muitos subsídios para saber se e como seria possível pagar o empréstimo realizado. Contudo, acreditou que esse se fazia necessário para o crescimento da empresa.

Uma explicação complementar ao código pode ser registrada em um comentário (comment) ligado ao código, conforme apresentado na Figura 3. 
Figura 3 Exemplo de comentário para código

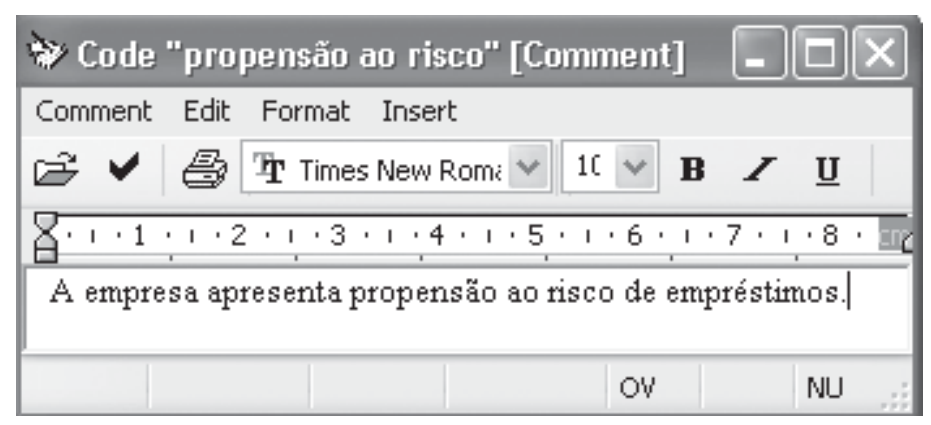

O exemplo exposto na Figura 3 permite ponderar que os comentários podem ser empregados para registrar uma informação complementar a respeito do elemento ao qual estão vinculados, no caso, a um código, bem como para registrar outros comentários que o pesquisador julgue relevantes, como o significado do elemento, a sua importância, a justificativa para sua criação e outros. Bandeira-de-Mello e Cunha (2003) sugerem que os pesquisadores utilizem as notas de análise para registrar o "caminho" seguido durante as análises (raciocínio, comparações, insights, etc.). O registro dessas informações em comentários pode ser essencial para o pesquisador no decorrer das análises e poderá ser acessado facilmente, além de servir de explicação complementar no caso de outro pesquisador também trabalhar com a mesma unidade hermenêutica.

Na Figura 4, apresenta-se mais um exemplo de codificação. 
Figura 4 Exemplo de codificação

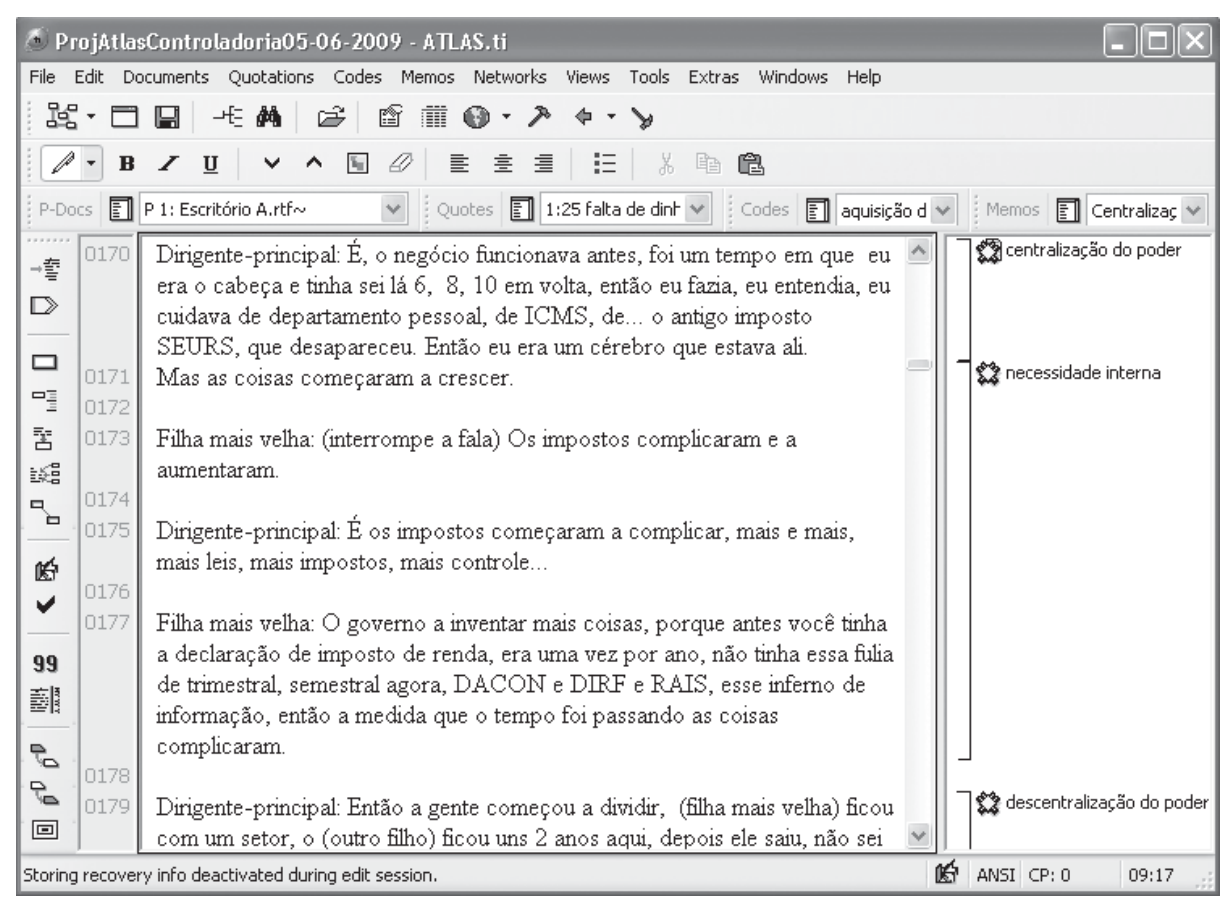

Na Figura 4 encontram-se exibidos três códigos: centralização do poder, necessidade interna e descentralização do poder. Diferente do exemplo apresentado na Figura 2, tais códigos não foram obtidos diretamente das teorias de base, mas foram considerados importantes e relacionados às teorias (como será exposto a seguir), em consonância com o indicado por Ferreira et al. (2012) de que os códigos podem ser obtidos do referencial teórico, do objetivo da pesquisa, das hipóteses de pesquisa ou emergirem dos dados.

Em relação ao conjunto dos três códigos expostos na Figura 4, ressaltase que o dirigente principal detinha o poder no tocante ao escritório (centralização do poder), o que pode ser associado à dimensão comando do processo de desenvolvimento de estratégias, na qual a estratégia é definida e determinada por um indivíduo poderoso da organização (BAILEY; AVERY, 1998). Contudo, em virtude de necessidades internas oriundas 
do crescimento da empresa e da ampliação das exigências, o dirigente principal iniciou um processo de descentralização do poder, dividindo as responsabilidades e gestão com seus filhos. Dessa forma, é possível estabelecer uma nota de análise (memo) para registrar essas informações, de acordo com o que se expõe na Figura 5.

Figura 5 Exemplo de nota de análise (memo)

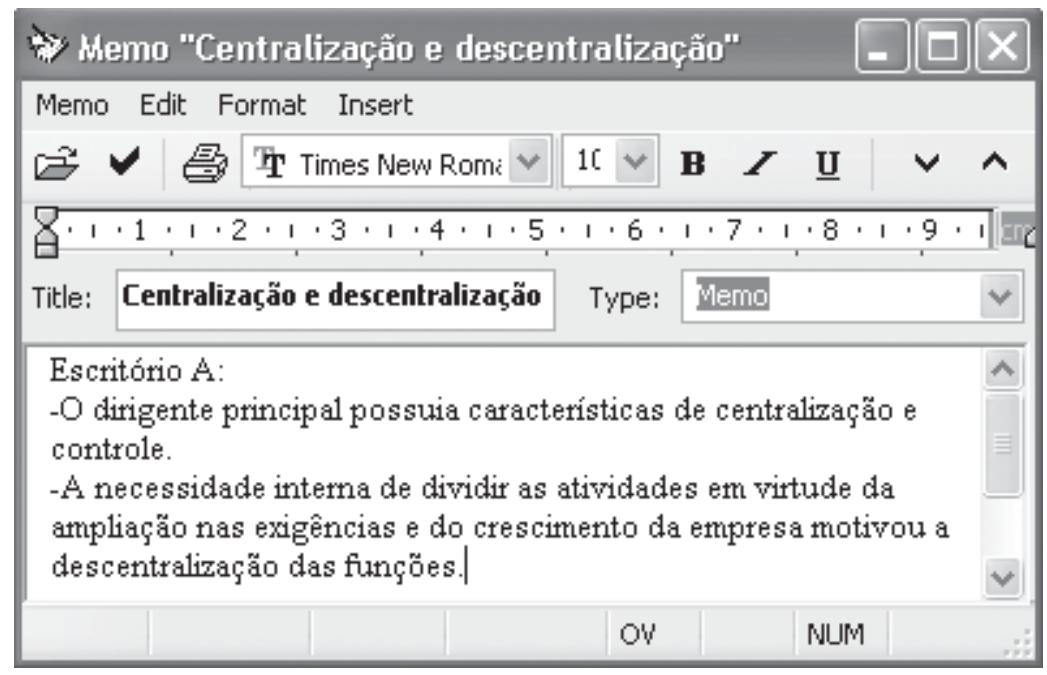

De acordo com o que se pode observar na Figura 5, uma nota de leitura (memo) pode ser utilizada para a síntese e o agrupamento de informações relevantes para a pesquisa que podem ser empregadas posteriormente.

Na Figura 6, apresenta-se um exemplo de relação entre duas citações (anchor ou âncora). 
Figura 6 Exemplo de relação entre quotation

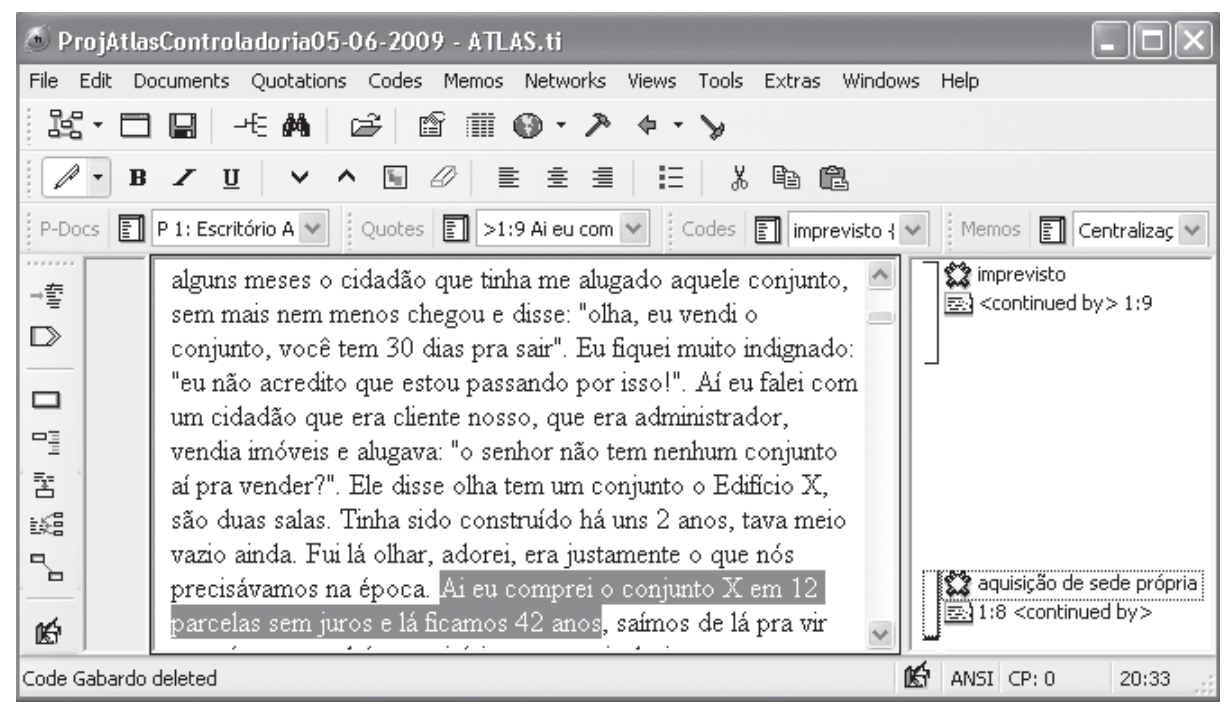

Percebe-se, com base na Figura 5 que em virtude de um imprevisto (venda do imóvel alugado que sediava a empresa), o proprietário efetuou a compra de uma sede própria para a empresa. Esse tipo de relação pode ser retomado posteriormente pelo pesquisador, facilitando o processo de organização e análise das informações relevantes (CANTERO, 20I4).

Na Figura 7, apresenta-se uma relação entre códigos (link) utilizando, para isso, a representação gráfica. 
Figura 7 Representação gráfica de uma relação entre códigos

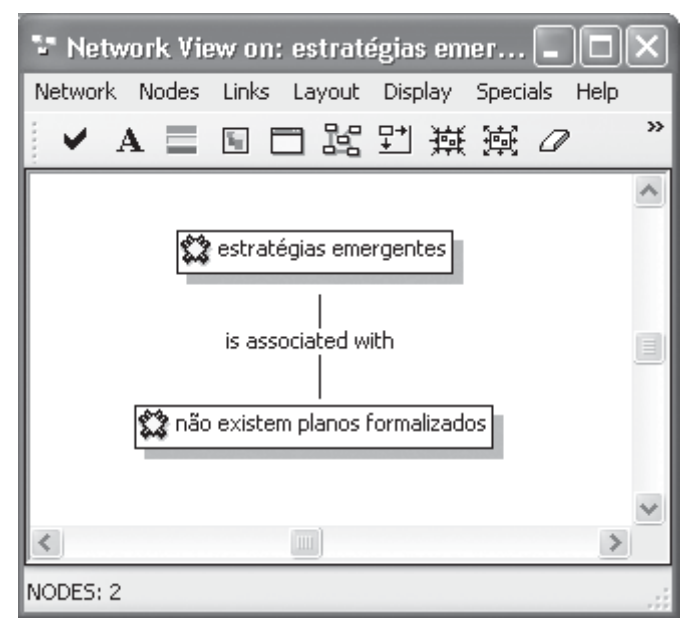

Por meio da Figura 6, verifica-se que a indicação dos dirigentes dos escritórios analisados de que as estratégias são emergentes está associada à inexistência de planos formalizados, como destaca um dirigente do Escritório A: "O planejamento é da diretoria. Às vezes surge uma e outra ideia, então é discutido entre nós, se é boa ou não. Mas as coisas não estão no papel”. As representações gráficas são uma das vantagens oferecidas pelo Atlas.ti no que se refere a facilitar a visualização das relações estabelecidas e auxiliar no processo de interpretação (FERREIRA et al., 20I2).

O Atlas.ti também permite importar vizinhos (neighbors) dos elementos na visualização gráfica, conforme Figura 8. 
Figura 8 Exemplo de representação gráfica de citações de códigos

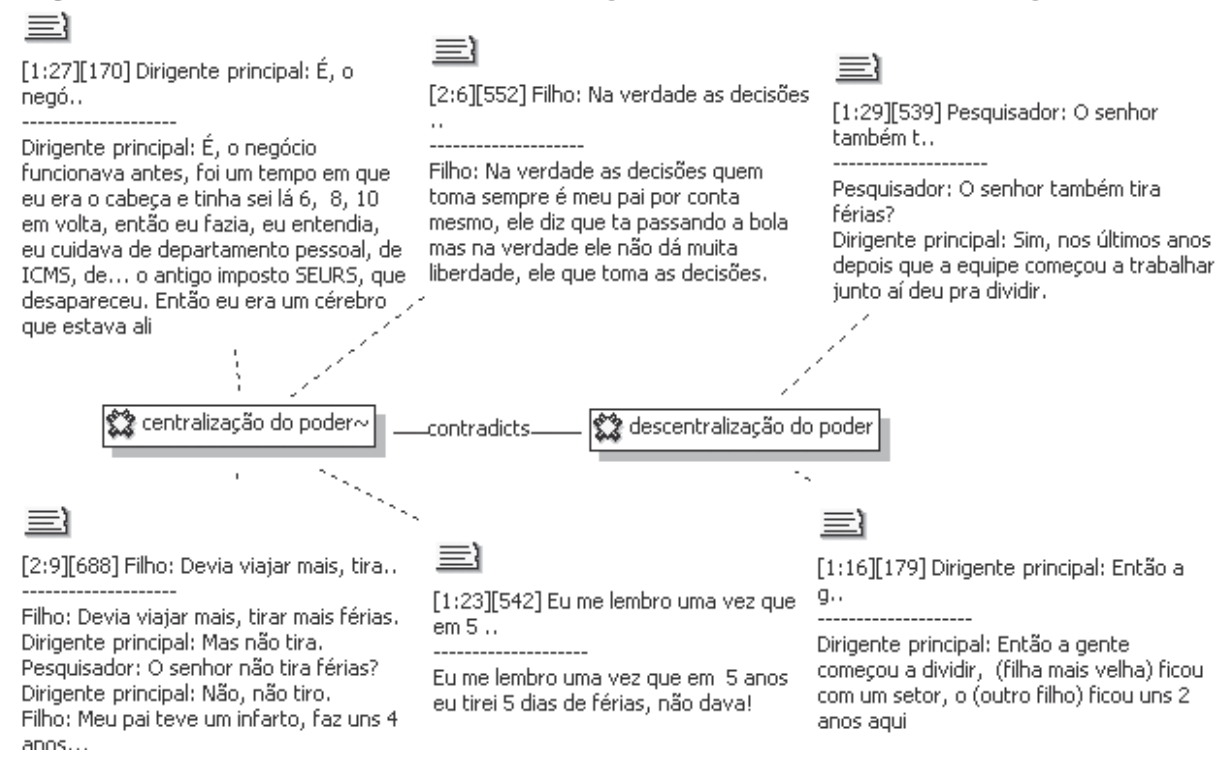

A Figura 8 deixa perceptível que existem quatro citações vinculadas ao código centralização do poder e duas ao código descentralização do poder. Percebe-se que ambos os dirigentes principais apresentam características de centralização do poder e que, contudo, o dirigente do Escritório A, visualizado por meio do número I referente a Pi no início da citação [I:xx], iniciou um processo de descentralização. Essa ferramenta do software facilita o resgate das citações para análise.

Outra opção do Atlas.ti é agrupar os códigos em famílias ( family) e gerar esquemas gráficos (networks) dessas famílias, em conformidade com o que se expõe na Figura 9. Nessa direção, Cantero (20I4) elucida que o Atlas.ti possibilita a construção de diagramas para apresentar relações complexas. 
Figura 9 Representação gráfica da família de códigos do Escritório A

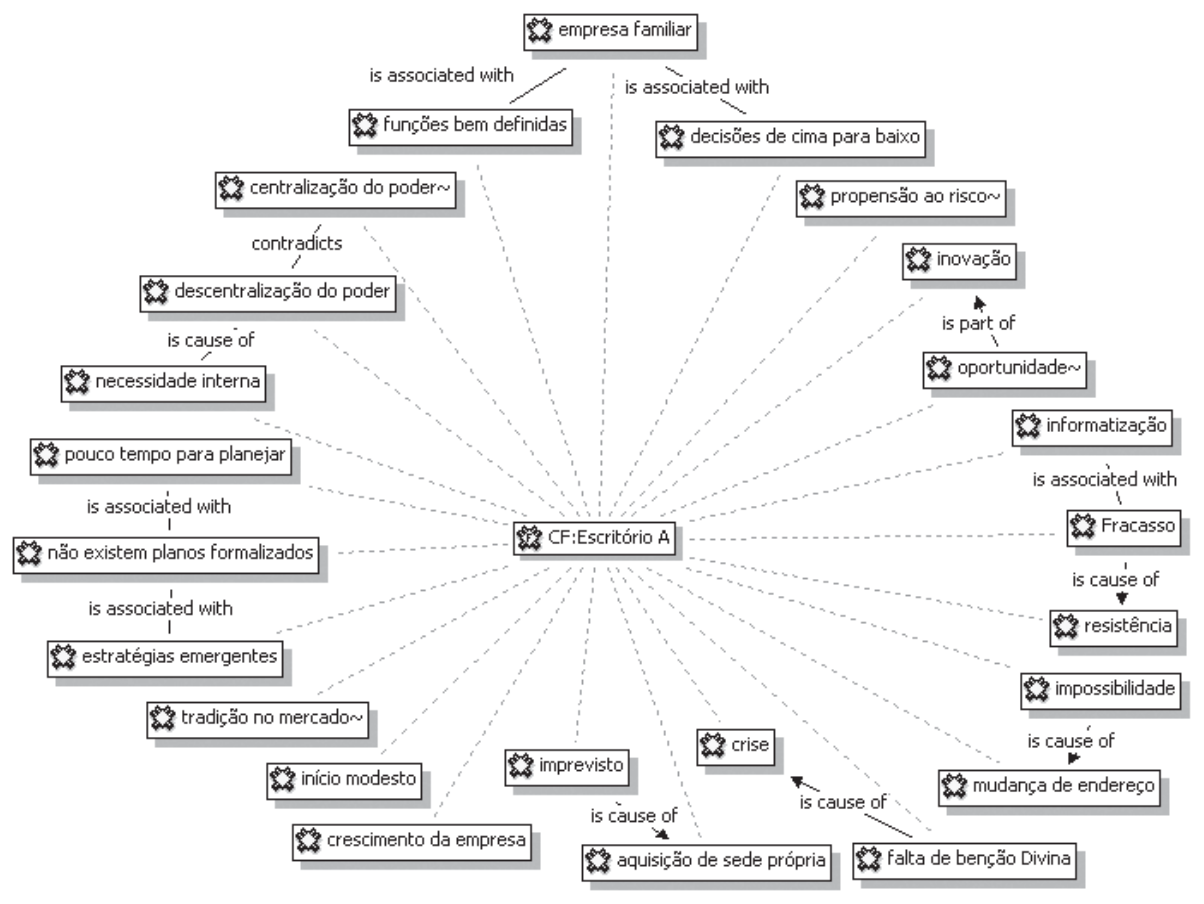

A Figura 9 na qual é apresentada a representação gráfica da família de todos os códigos vinculados ao escritório A, permite analisar que o Escritório A é uma empresa familiar, cujas funções são bem definidas. O poder era centralizado na figura de seu dirigente principal, mas, em virtude de uma necessidade interna - visto o aumento das exigências e o crescimento da empresa -, esse acabou iniciando um processo de descentralização do poder e dividindo as funções com seus filhos. Anteriormente a essa descentralização e inserção dos filhos na empresa, o processo de desenvolvimento de estratégia nesse escritório era influenciado pelo que Bailey e Avery (1998) denominam de comando. Além disso, apesar de o poder estar mais descentralizado, as decisões continuam a ser tomadas de cima para baixo, ou seja, pela família/ diretoria e comunicada aos colaboradores.

A empresa apresenta propensão ao risco na realização de empréstimos e promoveu algumas inovações no decorrer de sua trajetória, sendo uma 
delas motivada por uma oportunidade oriunda de um convite da Caixa Econômica Federal para testar a Conectividade Social. Essa propensão à inovação e propensão ao risco são duas características destacadas por Carland, Carland e Hoy (1992) quanto ao comportamento empreendedor. Contudo, a primeira tentativa de informatização fracassou, fato que gerou uma resistência do Escritório $\mathrm{A}$ à segunda tentativa.

Os dirigentes do Escritório A destacam que possuem pouco tempo para planejar, o que pode explicar, ao menos parcialmente, a inexistência de planos formais. Assim, a maior parte das estratégias é emergente, o que vai ao encontro do que destacam Bailey e Avery (1998) sobre o processo de desenvolvimento de estratégias de forma incremental.

No que tange a sua cronologia, o Escritório A iniciou suas atividades em 1952, mostrando-se uma empresa tradicional no mercado. O início foi modesto, com poucos funcionários, mas aos poucos a empresa cresceu. Um imprevisto (venda do imóvel alugado em que a empresa se localizava) motivou a aquisição de sua sede própria. Em seguida, o escritório enfrentou uma crise que fez com que seu dirigente principal cogitasse a venda do escritório. A explicação fornecida pelo dirigente principal no tocante a essa crise é que ocorreu em virtude da falta de uma benção Divina. A empresa mudou mais uma vez de endereço, dessa vez motivada pela impossibilidade de adquirir mais uma sala no prédio em que se localizava para expandir o escritório. Percebe-se que, ao longo de sua trajetória, a empresa realizou mudanças e que as atribui a fatores externos à atuação e à vontade de seus dirigentes. É possível relacionar esse resultado ao apontado por Bailey e Avery (1998) sobre a escolha imposta.

Na Figura Io, exibe-se a representação gráfica da família dos códigos do Escritório B. As famílias, segundo, Ferreira et al. (2010), podem ser compreendidas como a classificação, a diferenciação e o reagrupamento dos elementos de acordo com critérios de análise. Nesse caso, o critério utilizado foi contemplar os códigos relacionados ao Escritório B. 
Figura ro Representação gráfica da família de códigos do Escritório B

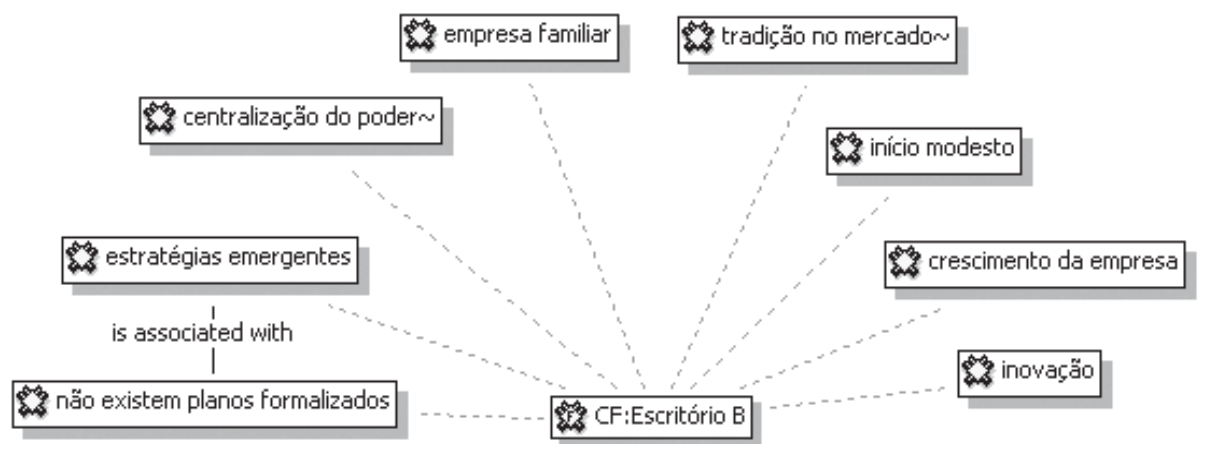

A Figura ro possibilita perceber que o Escritório B, a exemplo do Escritório A, consiste em uma empresa familiar. Entretanto, o dirigente principal ainda centraliza o poder, o que apresenta uma característica de comando (BAILEY; AVERY, 1998) no processo de formação de estratégias. A empresa surgiu em 1968, o que também revela sua tradição no mercado e, embora tenha tido um início modesto, cresceu.

Os dirigentes do Escritório B destacam uma inovação ocorrida no tocante à integração dos sistemas, embora, de forma geral, não apresentem muitas das características apontadas por Carland, Carland e Hoy (1992) de comportamento empreendedor.

No Escritório B, não existem planos formalizados, e a maior parte das estratégias é emergente, ou seja, o processo de formação de estratégias também é incremental (BAILEY; AVERY, 1998).

Como visto nesta subseção, o Atlas.ti permite o agrupamento de famílias por meio da criação de uma superfamília (super family). Para tanto, esse software fornece quatro opções de agrupamento dos elementos que compõem as famílias: OR (agrupa todos os elementos de todas as famílias selecionadas); XOR (apresenta os elementos que são diferentes entre as famílias selecionadas); AND (apresenta os elementos que são iguais entre as famílias selecionadas); e NOT (apresenta os elementos que não estão presentes na família ou famílias selecionadas).

Na Figura II, tem-se a representação gráfica da superfamília dos códigos iguais entre as famílias do Escritório A e do Escritório B, obtida por meio da opção AND. 
Figura II Representação gráfica da superfamília de semelhanças entre o Escritório A e o Escritório B

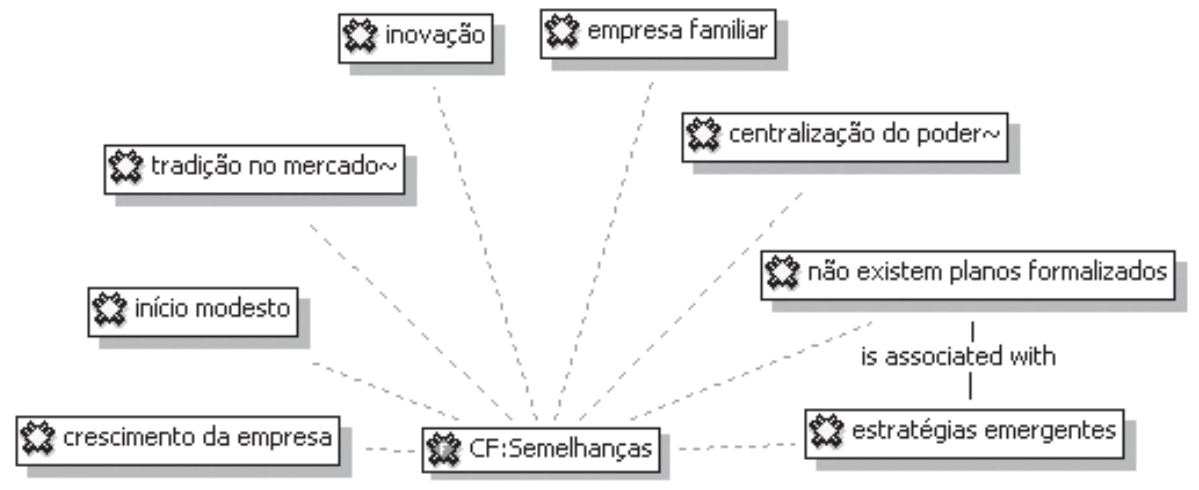

Por meio da Figura II, percebe-se que os dois escritórios de contabilidade possuem uma trajetória similar, visto que atuam há vários anos no mercado, iniciaram suas atividades de forma modesta e cresceram com o tempo. Além disso, caracterizam-se como empresas familiares, mas possuem (Escritório B) ou possuíam o poder concentrado nas mãos de seus dirigentes principais (Escritório A). Ambos realizaram inovações no decorrer de sua existência, apesar de o Escritório A aparentar ser mais inovador que o Escritório B. Além disso, os dois escritórios não possuem planos formalizados, e a maior parte de suas estratégias é emergente.

Na Figura I2, por sua vez, exemplifica-se a codificação de uma reportagem jornalística sobre o Escritório A, parte integrante da pesquisa documental, inserida no Atlas.ti em forma de imagem. 
Figura I2 Exemplo de codificação de reportagem jornalística

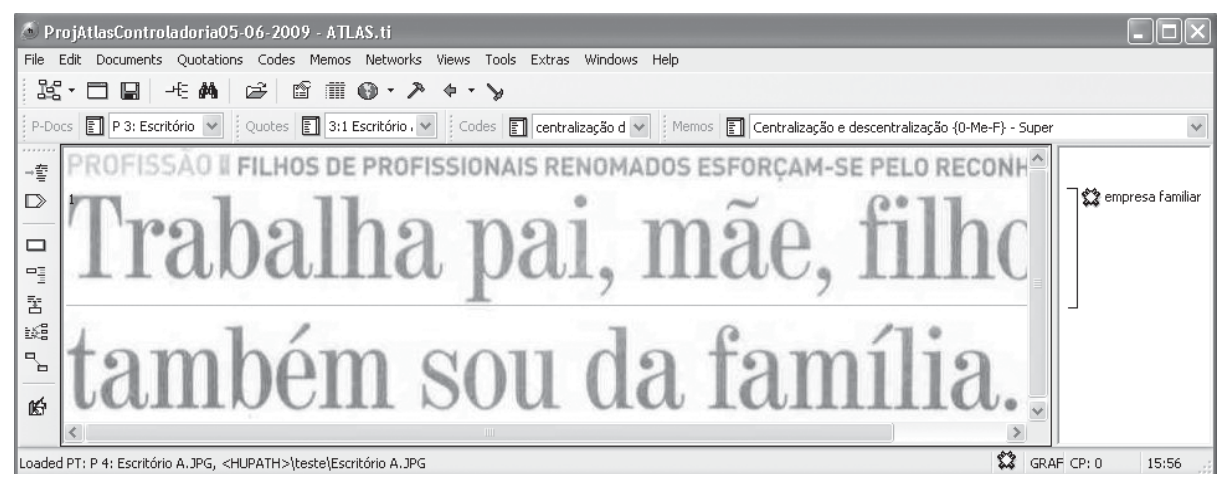

Por meio da Figura 12, observa-se que a reportagem jornalística veiculada a respeito do Escritório A reforça a caracterização desse escritório como empresa familiar. Cabe lembrar que o Atlas.ti possibilita a incorporação de diferentes tipos de documentos (texto, áudio, imagens e vídeos) (LEITE, 20I3; CANTERO, 20I4). Isso facilita o arquivamento dos documentos e é útil para a triangulação de dados em um estudo de caso, por exemplo.

Além das opções apresentadas nas figuras e comentários expostos, o Atlas. ti oferece uma ampla diversidade de ferramentas e possibilidades que podem ser importantes de acordo com o objetivo, a teoria, a metodologia e os dados empregados, como a construção de redes semânticas (network) sem partir de uma família, visualização de citações e comentários na representação gráfica, análise de co-ocorrências (cooccuring), emissão de relatórios, divisão da unidade hermenêutica em duas, fusão de duas unidades hermenêuticas em uma, ferramentas de busca (query tools), contar palavras (word cruncher), autocodificação (auto-coding) e outras. 


\section{CONSIDERAÇÕES FINAIS}

Este estudo teve por objetivo apresentar, por meio de um exemplo, a aplicabilidade do software Atlas.ti na realização de análise de conteúdo do tipo temática na área de estratégia. Optou-se, como exemplo, por uma pesquisa com base teórica sobre o processo de desenvolvimento de estratégia e a atitude empreendedora aplicada a dois escritórios de contabilidade de Curitiba, Paraná.

Este estudo possibilitou apresentar o processo de codificação, criação de notas de pesquisa e de comentários, estabelecimento de relações entre elementos analisados e o agrupamento desses elementos, bem como a visualização gráfica de tais procedimentos. As ações descritas e diversas outras podem ser realizadas pelo pesquisador com o auxílio do software Atlas.ti, conforme exemplificado, o que atribuirá agilidade e precisão à pesquisa.

O emprego do software Atlas.ti se mostrou adaptável ao objetivo, à teoria, à metodologia e aos dados do exemplo empregado. Por meio desse software, foi possível não só agrupar em um único projeto as duas entrevistas realizadas, mas também realizar a padronização dos códigos e, consequentemente, estabelecer uma comparação entre os dois escritórios enfocados, a qual permitiu apontar semelhanças e diferenças entre ambos. A análise temática de conteúdo foi facilitada e agilizada com o emprego desse software, haja vista a maior facilidade e a rapidez para estabelecer os rótulos necessários às unidades de registro. Outro aspecto facilitado pelo software foi o retorno, durante o processo, às etapas anteriores de análise para avaliá-las e obter novos insights. Em síntese, com base nos procedimentos realizados com o software Atlas.ti, foi possível analisar em separado os dois escritórios de contabilidade pesquisados, bem como compará-los, por meio de representações gráficas, o que facilitou o processo de análise.

Com base no exemplo de análise apresentado, é possível afirmar que não se engessa ou se automatiza o processo de análise de uma pesquisa com o uso do Atlas.ti, mas que somente se gerenciam todos os arquivos de um projeto de pesquisa em uma única unidade hermenêutica de modo 
informatizado, dispensando marca-textos, papel, cola e tesoura. O Atlas.ti não reduz o papel e a importância do pesquisador no processo de interpretar e analisar; apenas facilita sua operacionalização, pois trata-se de uma ferramenta moderna que auxilia análises mais profundas, facilitando a localização simultânea de múltiplos dados.

Destaca-se que o exemplo apresentado consiste apenas em umas das possibilidades de análise com o auxílio do Atlas.ti. Dessa forma, sugerese o emprego do Atlas.ti em outras pesquisas qualitativas da área de estratégia, visto que esse software é pouco aproveitado para auxiliar no desenvolvimento de estudos nesses campos. Acredita-se que o Atlas.ti possa ser útil em pesquisas sobre diferentes temáticas da área, sendo essencial, todavia, avaliar sua adequação ao método escolhido.

Além disso, entre as pesquisas que citam a utilização do Atlas.ti na descrição dos procedimentos metodológicos, a maior parte pouco esclarece sobre como e por que se deu o emprego nem sobre as vantagens e desvantagens do software percebidas pelos pesquisadores no decorrer do estudo. Também podem ser realizados estudos comparando diferentes softwares de análise de dados qualitativos em pesquisas com diferentes métodos, objetivos e perspectivas para explorar as indicações, as vantagens e as desvantagens de cada software.

Espera-se que este estudo estimule a utilização de softwares de análise de dados qualitativos, como o Atlas.ti, expandindo o número de pesquisas qualitativas que ainda se apresenta restrito à área, bem como contribua para a melhoria da qualidade dos estudos realizados, ampliando sua consistência por meio da facilidade de verificação empírica das interpretações, assim como do registro e do retorno às etapas da análise. 


\section{REFERÊNCIAS}

ATLAS.TI. Software. Disponível em: <www.atlasti.com>. Acesso em: 05/06/2013.

BARDIN, L. Análise de conteúdo. Lisboa: Edições 70, 2002.

BAILEY, A.; AVERY, C. Discovering and defining the process of strategy development. In: AMBROSINI, V.; JOHSON, G.; SCHOLES, K. (Coord.). Exploring techniques of analysis and evaluation in strategic management. Harlow: Pearson Education, 1998. BANDEIRA-DE-MELLO, R. Softwares em pesquisa qualitativa. In: GODOI, C. K.; BANDEIRA-DE-MELLO, R.; SILVA, A. B. da. (Org). Pesquisa qualitativa em estudos organizacionais: paradigmas, estratégias e métodos. São Paulo: Saraiva, 2006.

BANDEIRA-DE-MELLO, R.; CUNHA, C. J. C. de A. Operacionalizando o método da grounded theory nas pesquisas em estratégia: técnicas e procedimentos de análise com apoio do software Atlas/ti. In: 3Es, 1., 2003, Curitiba. Anais... Curitiba: Anpad, 2003.

CANTERO, D. S. M. Teoría fundamentada y Atlas.ti: recursos metodológicos para la investigación educativa. Revista Electrónica de Investigación Educativa, v. 16, n. 1, p. 104-122, 2014.

CARLAND, J. W.; CARLAND, J. C.; HOY, F. S. An entrepreneurship index: an empirical validation. Frontiers of Entrepreneurship Research, v. 25, n. 3, p. 244-265, 1992.

DOLAN, A.; AVLAND, C. Analysis on trial. International Journal of Market

Research. v. 43, n. 4, p. 377-389, 2001.

FERREIRA, I. do R. C.; VOSGERAU, D. S. R.; MOYSÉS, S. J.; MOYSÉS, S. T. Diplomas Normativos do Programa Saúde na Escola: análise de conteúdo associada à ferramenta ATLAS TI. Ciência \& Saúde Coletiva, v. 17, n. 12, p. 3385-3398, 2012.

GILBERT, L. Going the distance: 'closeness' in qualitative data analysis software.

International Journal of social research Methodology, v.5, n.3, p.215-228, 2002.

LEITE, Y. V. P. Teoria Adaptativa e Atlas.ti 7: uma Parceria para o Desenvolvimento de Framework de Empreendedorismo Internacional. In: EnANPAD, 37., 2013. Rio de Janeiro. Anais... Rio de Janeiro: Anpad, 2013.

MUHR, T. ATLAS/ti: a prototype for the support of text interpretation. Qualitative Sociology, v.14, n.4, p. 349-371, 1991.

RICHARDS L.; RICHARDS, T. The transformation of qualitative method: computational paradigms and research processes. In: FIELDING, N. G.; LEE, R. M. (Eds.). Using Computers in Qualitative Research. London: Sage, 1991, p.38-53. 


\section{DADOS DOS AUTORES}

SILVANA ANITA WALTER ${ }^{\star}$ silvanaanita.walter@gmail.com Doutora em Concentração em Administração Estratégica pela PUC/PR Instituição de vinculação: Universidade Estadual do Oeste do Paraná Marechal Cândido Rondon/PR - Brasil

Áreas de interesse em pesquisa: Estratégia e Métodos de Pesquisa.

${ }^{\star}$ Rua Presidente Costa e Silva, 909 Konrad Marechal Cândido Rondon/PR 85960-000

\section{TATIANA MARCEDA BACH tatibach@gmail.com}

\section{Mestre em Administração pela FURB}

Instituição de vinculação: Pontifícia Universidade Católica do Paraná

Curitiba/PR - Brasil

Áreas de interesse em pesquisa: Métodos de pesquisa em Administração,

Administração Estratégica e Teoria Institucional. 